\title{
BÁcolnternational.

\section{A critical appraisal of key evidence for grommet insertion to manage recurrent acute otitis media in children}

\section{Background}

Recurrent acute otitis media (RAOM) is defined by Goycoolea et al, as cited by McDonald et al, ${ }^{1}$ as $\geq 3$ episodes of AOM in 6 months or $\geq 4$ in 12 , with disease-free intervals. This excludes children with otitis media with effusion. ${ }^{1}$

\section{Objective}

To critically appraise the best 3 available publications assessing the outcomes for grommet insertion in the management of RAOM in children.

\section{Methods}

Medline (1946 to present) and the Cochrane Library were searched using a systematic strategy (figure 1 ) to locate publications addressing the following:

Population: all children with RAOM

Intervention: bilateral grommet insertion

Comparison: no intervention

Outcome: global improvement in terms of AOM recurrence and quality of life (QOL)

$$
\text { Results }
$$

Figure 2 shows search results and papers deemed relevant. Those originally chosen for appraisal included McDonald et al's ${ }^{1}$ Cochrane review and 2 studies by Kujala et al..$^{2,3}$ Kujala et al's ${ }^{2,3} 2$ studies are the same randomised controlled trial (RCT) but they present different outcomes. They were the only identified studies conducted after McDonald et al's ${ }^{1}$ review was updated in 2011 . Since this appraisal was originally completed, McDonald et al's ${ }^{1}$ review has been updated by Venekamp et al, ${ }^{4}$ thus this review is appraised here. Venekamp et $\mathrm{al}^{4} \mathrm{~s}^{4}$ review includes both publications by Kujala et $\mathrm{al}^{2,3}$ as one study. However, these publications ${ }^{2,3}$ are still discussed here because, out of 24 potentially relevant publications identified by Venekamp et $\mathrm{al}^{4}{ }^{4}$ there were no more recent RCTs than that conducted by Kajula et al.2,3

Venekamp at $\mathrm{al}^{4}$ studied children $\leq 16$ years old with RAOM and compared grommets to active monitoring, antibiotic prophylaxis or placebo. They found 5 relevant studies of which Gebhart (1981) and Kujala et al (2012) addressed grommets compared to monitoring (see table). Following Cochrane guidance on bias risk assessment, $46 \%$ of risk of bias items were deemed 'high' and $46 \%$ 'unclear'. In Gebhart, performance and detection biases were deemed 'high' and, in Kujala et al, performance, detection and reporting biases 'high'. Despite these high levels of bias risk the review was very methodologically robust.

Kujala et al ${ }^{2}$ studied 300 children in 3 arms of 100,2 being grommets and control (see table). 2 episodes of AOM in 2 months, 3 in 6 or effusion for 2 was defined as failure. One inclusion criteria was residence within 25 miles which may affect generalisability of results. Intention to treat analysis was performed but no sensitivity analysis despite some loss to follow up. Blinding was not described ${ }^{2}$ but blinding of surgical procedures like grommets is not possible. ${ }^{1}$ Kujala et al ${ }^{3}$ studied the last 159 of the 300 children above, 105 of which were in the relevant arms and 77 of these finally analysed (see table). This study assessed QOL using an OM specific questionnaire (OM-6 - a well recognised valid tool). Participants analysed were those who replied to either all 3 questionnaires (entry, 4 and 12 months) or the first and last. This 'loss to follow up' gives a risk of attrition bias. There was no sensitivity analysis.
Oliver Penfold, University of Bristol

\author{
1. $\exp$ Otitis Media/ \\ 2. exp Otitis Media, Supprative/ \\ 3. acute otitis media.mp. \\ 4. otitis media.mp. \\ 5. middle ear infection.mp. \\ 6. 1 or 2 or 3 or 4 or 5 \\ 7. recurrent.mp. \\ 8. 6 and 7 \\ 9. exp Middle Ear Ventilation/
}

10. myringotomy.mp.

11. tympanostomy.mp.

12. pressure equalization.mp.

13. grommet?.mp.

14. 9 or 10 or 11 or 12 or 13

15. 8 and 14

16. limit 15 to (english language and full text and humans and "all child (0 to 18 years)" and clinical trial, all)

Figure 1: systematic search strategy used.

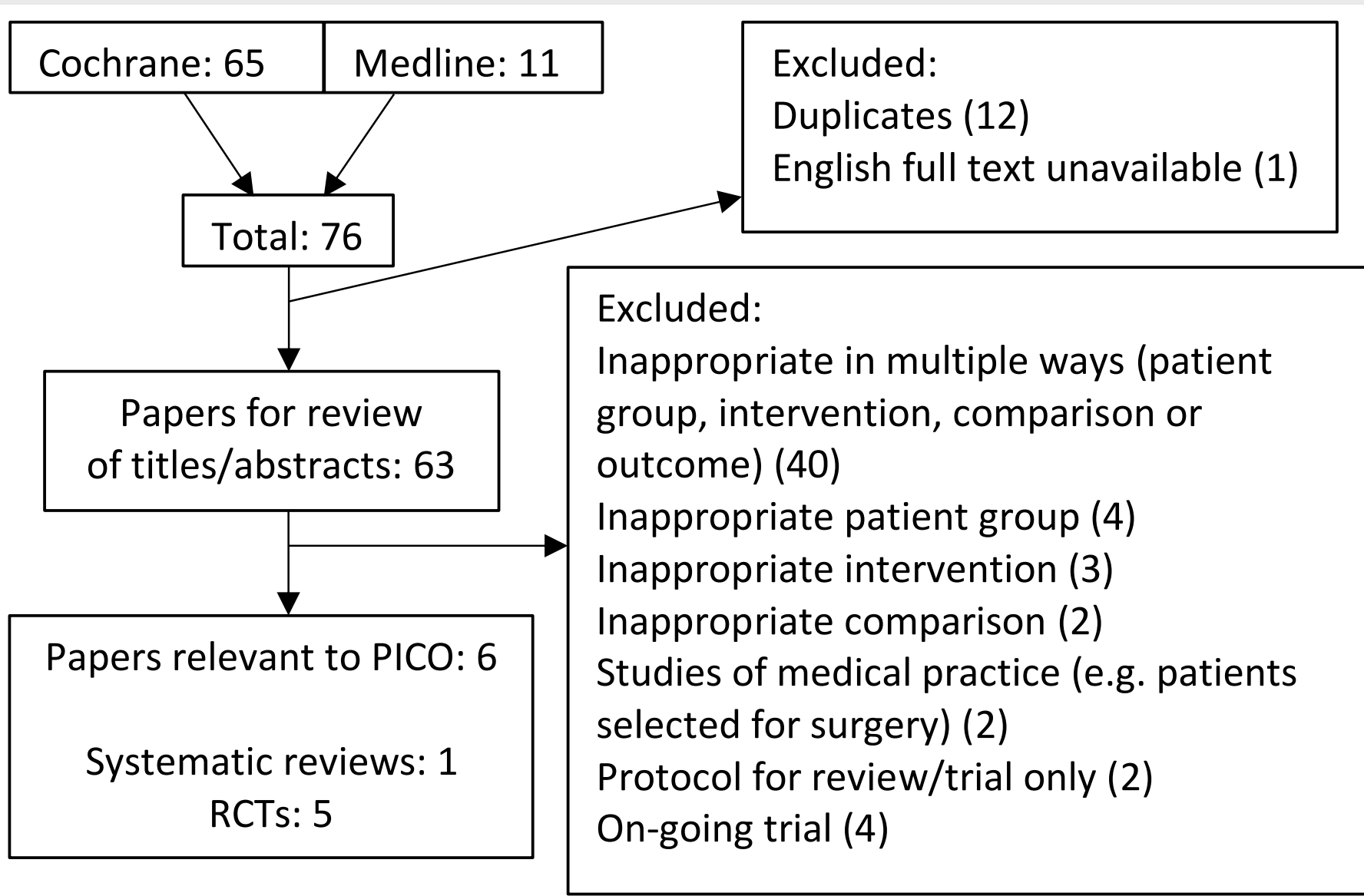

Figure 2: flow chart showing search results.

\section{Conclusion}

From the evidence appraised it can be concluded that grommets offer a good chance of freedom from recurrence and reduced recurrences at 6 and 12 months. However the benefit is not overly significant especially when considering mean recurrences per child. ${ }^{2,4}$ It is also apparent that grommets do not improve QOL though they reduce recurrences. ${ }^{3}$ Most of the confidence intervals and $p$-values show the data is not very strong. ${ }^{2,4}$ Considering this and the risk of bias in the studies, ${ }^{4}$ confidence is limited in these conclusions.

\begin{tabular}{|c|c|c|c|c|c|c|}
\hline Paper & Sample reported & Intervention & Outcomes & Follow up & Results & Significance \\
\hline $\begin{array}{l}\text { Venekamp et } \\
\mathrm{al}^{4} \text { (Gebhart) }\end{array}$ & $95, \leq 3$ years old & Grommets vs AM & $\begin{array}{l}\text { a) Proportion having no } \\
\text { recurrences and b) total } \\
\text { recurrences }\end{array}$ & 6 months & $\begin{array}{l}\text { a) Risk of recurrence: } \\
\text { RR=9.49 } \\
\text { b) mean difference: }-1.5\end{array}$ & 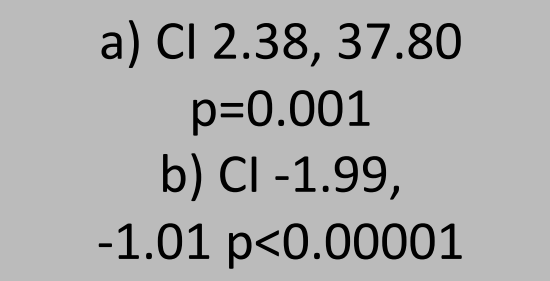 \\
\hline Kujala et $\mathrm{al}^{2}$ & $200,10-24$ months & $\begin{array}{l}\text { Grommets vs } \\
\text { control }\end{array}$ & $\begin{array}{l}\text { a) As above and b) } \\
\text { Number of failures }\end{array}$ & 1 year & $\begin{array}{l}\text { a) Difference: } 14 \% \\
\text { b) Difference: }-13 \%\end{array}$ & $\begin{array}{l}\text { a) } \mathrm{Cl} 0.3,27 \mathrm{p} \text { not given } \\
\text { b) } \mathrm{Cl}-25,-1 \mathrm{p}=0.04\end{array}$ \\
\hline Kujala et $\mathrm{al}^{3}$ & $77,10-24$ months & As above & QOL & 1 year & no difference & - \\
\hline
\end{tabular}

Table: Summary of studies. $A M=$ active monitoring, $R R=$ risk ratio, $C l=95 \%$ confidence interval, $Q O L=$ quality of life

References:

1. McDonald S, Langton Hewer CD, Nunez DA. Grommets (ventilation tubes) for recurrent acute otitis media in children. Cochrane Database of Systematic Reviews. 2008, 4. Art. No.: CD004741.

2. Kujala T, Alho OP, Luotonen J, Kristo A, Uhari M, Renko M, Kontiokari T, Pokka T, Koivunen P. Tympanostomy with and without adenoidectomy for the prevention of recurrences of acute otitis media: a randomized controlled trial. The Pediatric infectious disease journal. 2012;31(6):565-569.

3. Kujala T, Alho OP, Kristo A, Uhari M, Renko M, Pokka T, Koivunen P. Quality of life after surgery for recurrent otitis media in a randomized controlled trial. The Pediatric infectious disease journal. 2014;33(7):715-719.

4. Venekamp RP, Mick P, Schilder AGM, Nunez DA. Grommets (ventilation tubes) for recurrent acute otitis media in children. Cochrane Database of Systematic Reviews. 2018, 5. Art. No.: CD012017. 